\title{
Study on Spatial Measurement and Influence Mecha- nism of the Correlation between Traditional Villages and River Systems:A case study of Hunan, China
}

\author{
Suifeng Zhang \\ Central South University \\ difei jiang ( $\square$ difeijiang_1619@126.com ) \\ Hunan University of Technology
}

\section{Research Article}

Keywords: Traditional villages, River systems, Correlation measurement, Spatial features, Influence mechanism, Hunan Province

Posted Date: September 24th, 2021

DOl: https://doi.org/10.21203/rs.3.rs-919457/v1

License: (c) (1) This work is licensed under a Creative Commons Attribution 4.0 International License. Read Full License 


\title{
Study on Spatial Measurement and Influence Mecha- nism of the Correlation between Traditional Villages and River Systems:A case study of Hunan, China
}

\author{
Suifeng Zhang ${ }^{\mathrm{ac}}$,Difei Jiang ${ }^{\mathrm{b}}$ \\ ${ }^{a}$ Ph.D.Student,Dept.of Architecture and Art,Central South University,Changsha 410083,China \\ (E-mail:fengsuizhang@163.com) \\ b Professor,Dept.of Architecture and Art,Central South University,Changsha 410083,China(E-m \\ ail:difeijiang_1619@126.com) \\ ${ }^{\mathrm{c}}$ Lecturer,Dept.of Urban and Environment, Hunan University of Technology,Zhuzhou 412007, \\ China(E-mail:fengsuizhang@163.com)
}

CORRESPONDENCE Difei Jiang, difeijiang_1619@126.com, Dept.of Architecture and Art,Ce ntral South University,Changsha 410083,China

\begin{abstract}
River systems acts as the critical factor for site selection. In the process of rural evolution, river adaptability created by human settlement is fading away due to inadequate understanding of inherent spatial characteristics. To better understand the inherent law of the applicability of traditional villages river systems, this study proposed the concept of inheritance based on spatial measurement of the correlation between traditional villages and river systems. With the help of GIS10.8 and SPSS26.0 software, this study takes 658 national traditional villages of Hunan and domestic river systems as an example to measure the spatial correlation characteristics, which concludes spatial pattern, spatial density and spatial distance. Summarize the similarity and differences characteristics of spatial distribution. Analyse and interpret the impact index of spatial correlation through the stepwise regression model. The results actually showed that traditional villages are uneven distributed along river systems, which are mainly affected by minority population, elevation and farming industry. In addition, traditional villages are less with the
\end{abstract}


increase of spatial distance from river systems. The values of spatial quantitative measurement and mechanism can reflect the traditional survival wisdom.It can guide significance for spatial growth mechanism of integration with environment and provide references for future conservation and utilization of spatial heritage sustainability.

\section{KEYWORDS}

Traditional villages; River systems; Correlation measurement; Spatial features; Influence mechanism; Hunan Province

\section{Introduction}

There are two concepts that reflect the the natural wisdom and spatial pattern of human sur$\operatorname{vival(Yang,2002;~Gao~et~al.,2021):one~is~that~people~prefer~to~live~by~rivers~in~ancient~tiomes,~the~other~}$ is that the philosophy of "the unity of heaven and human, the possession of wind and get water" is attached importance. It can be seen that river systems is the basis for the growth of traditional villages, and they are also the projection of spatial heritage, which represent the historical evolution from cruising lifestyle to agricultural civilization settlement(Hu et al.,2007).

The correlation between traditional villages and river systems is not only an important content of the ecological environment of settlement geography(Nigel \& Bob,2009;Jin,1988), but also the theoretical basis for the inheritance of settlement culture(Zhang,2012), which has always been concerned by academic. Relevant research is originated in the West. With the process of rural reconstruction and agricultural industrialization have been paid attention. German geographer J G Kohl is a pioneer in the study of settlement geography. He believes that environment of river systems affects site selection ( $\mathrm{Li} \&$ Zhang,2012); French geographers V Blache and J Brunhes believe that site selection for settlement is 
affected by the water demand of agricultural system(Lu,1935); Gilman, a Danish scholar, firstly believes that river systems is one of the elements of environment, advocates the integration of human activities, and also establishes the concept of "ecological village"(Gilman,1991). Then stone finds that river systems is the demand of agricultural farming and affects human settlement(Stone,1996); Palang believes that river systems is a kind of cultural landscape, and attention should be paid to the protection of water ecological to promote the integration of settlements and nature(Palang et al.,2003).

As the multicultural collage and functional transformation of traditional villages continue to be an issue(Feng \& Long,2020), the spatial correlation between traditional villages and river systems is facing many challenges: on the one hand, the spatial structure of river adaptability in traditional villages is recessively disappearing, and the concept of living near the river is gradually replaced by the trend along the road(Song et al.,2016); On the other hand, while tourism and other industrial can empower traditional villages, they also cause drainage pattern, water ecosystem damage and other phenomenas(Ji \& Ding,2019), resulting that the original structure of traditional villages and river systems is impacted. It is found that the research is mainly discussed as follows: one is to study the value of ritual culture, spring water resources, water landscape heritage, and water wisdom from the ontological value of river systems(Zhang,2015;Zhang \& Wang,2019; Yu \& Zhang,2007); The other is from the perspective of the interaction between traditional villages and river systems, which is to carry out site selection, spatial form evolution, spatial place, settlement spatial order and architectural art characteristics under the influence of river system elements(Zeng et al., 2020;Zhou,2015; Zhou,2008;Xin et al.,2020;Duan,2021). However, the research mainly focuses on the impact of river culture, river environment, river governance, river landscape at the meso and micro levels on the characteristics and evolution of spatial structure, and mostly adopts qualitative methods(Liu et al.,2017;Yang \& Wang,2020;Wu,2002;Liu \& Zhou,2004). 
With the deepening of rural transformation and the application of new technologies such as GIS and RS, the research from a quantitative perspective is gradually increasing. Some scholars believe that river systems is one of the indicatorsfor the evaluation of the spatial suitability of traditional settlements, and find that the distribution density of traditional settlements is related to the level of river systems, and shows differentiated evolution characteristics with the change of water system(Lu et al.,2017;Tang \& Zhao,2000; Li et al.,2017); Other scholars discuss the relationship from a full scale perspective and the survival relationship between the site selection of prehistoric settlements and river systems(zhang \& Wang,2017;Yan et al.,2017). Thus, the existing literature mainly studies and analyzes the morphological characteristics of settlement and river systems from the interactive dialectical level. However, generally speaking, there is still a lack of research on the characteristics and laws of the correlation between traditional villages and river systems, as well as the interpretation of the factors affecting spatial correlation.

In accordance with the abstracted spatial values, this study builds macro spatial perspective based on measured the spatial correlation characteristics of traditional villages and river systems. It can accurately reflect the local attribute of ecological space of "river+villages", and systematically study the influencing factors of their spatial correlation, which is of great significance for driving the spatial inheritance and development of traditional villages.

In response to the above questiones, this study attempts to take the longitude and latitude and domestic river system of 658 traditional villages in Hunan Province as the data source, extract their attribute information for mathematical statistics with the help of GIS10.8 spatial analysis method, so as to scientifically explain their spatial correlation characteristics. In addition, in order to better guide the construction activities of the modernization response of traditional villages and promote the spatial transformation and regeneration under the background of rural revitalization, the study reveals the wisdom texture of 
the coexistence of human activities and natural environment, and pays attention to the spatial heritage value of river adaptability.

\section{Material and Method}

\subsection{Study area}

Hunan Province is located in the hinterland of the middle reaches of the Yangtze River and the inner side of Nanling, which is abbreviated as "Xiang". The total area is approximately $211,800 \mathrm{~km}^{2}$. It has a subtropical humid monsoon climate with a latitude of $24^{\circ} 39^{\prime} \sim 30^{\circ} 08^{\prime} \mathrm{N}$ and a longitude of $108^{\circ} 47^{\prime} \sim 114^{\circ} 15^{\prime} \mathrm{E}$. In addition, it has a variety of landform types, and mountains account for more than $70 \%$ of its total area. Specifically, the landforms are divided into Wuling and Xuefeng Mountains in the west, Nanling Mountain in the south, Wugong, Luoxiao and Mufu Mountains in the east, hills in the center and Dongting Lake Plain. There are 185 rivers above 50km, 50 rivers above $100 \mathrm{~km}$ and 7 rivers above $500 \mathrm{~km}$, with water area of $6.4 \%$. In the evolution process of self-organization and hetero-organization, the spatial distribution of traditional villages in Hunan Province presents the characteristics of "multi center agglomeration", mainly distributed in the Wuling and Xuefeng Mountains in the west, and Nanling Mountain in the south (Li et al., 2015).

The Xiang, Zi, Yuan and Li rivers play an important role in military operations and are prospered due to trade. They all gather in Dongting Lake and flow into Yangtze River(Yin, 2010). Xiang River Basin developes with the earliest rice culture sites and Chengtou Mountain Site. It is the largest river running through its north and south, and an important tributary on the south bank of the middle reaches of the Yangtze River Basin; Zi River belongs to the Anhua Tea Horse Road Culture. Its middle and lower reaches are represented by hills and canyons, resulting in sharp rise and fall, with mostly pebbles and 
reefs in the riverbed. It flows into Dongting Lake via Ganxi Port in Yiyang city; Yuan River is the longest river in the province, with a total length of $1,033 \mathrm{~km}$. Its main tributaries are Wu River and You River, which cross east and west. Proved by the discovery of human activities since the late Paleolithic age, Yuan River Basin is serving as the node of economic and cultural exchanges between the east and the west of China and witnessing the 5,000 years of history in this region. Li River, named after the "green water in the 60km upper reaches", is the shortest one in the Yangtze River System. Its main tributaries are Loushui River, Xieshui River, Daoshui River and Censhui River. The upstream and middle reaches have intensive exploration, rapid flow and shallow water. The number of traditional villages in Hunan Province ranks third in China, and studies have found that $72 \%$ of traditional villages near river(Xu et al., 2020). It can be seen that the rich historical and cultural information and unique water ecological resources in Hunan Province have induced the growth of traditional villages, which is representative of a certain sample. (Zhang, 1995)

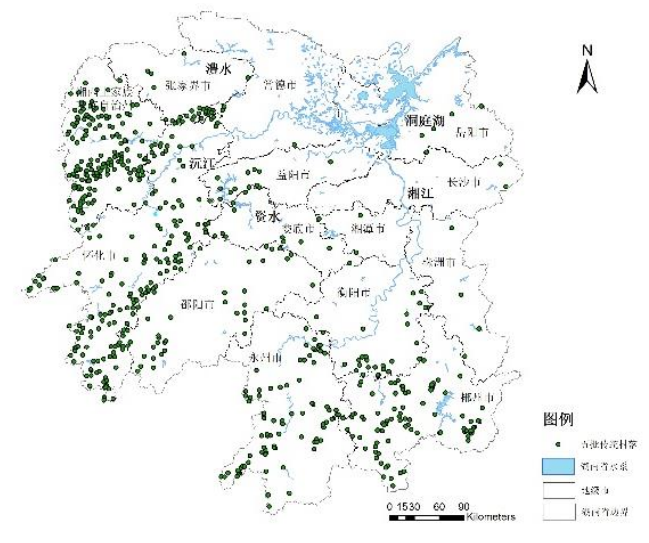

Fig. 1. Spatial Distribution of Traditional Villages and River Systems in Hunan Province

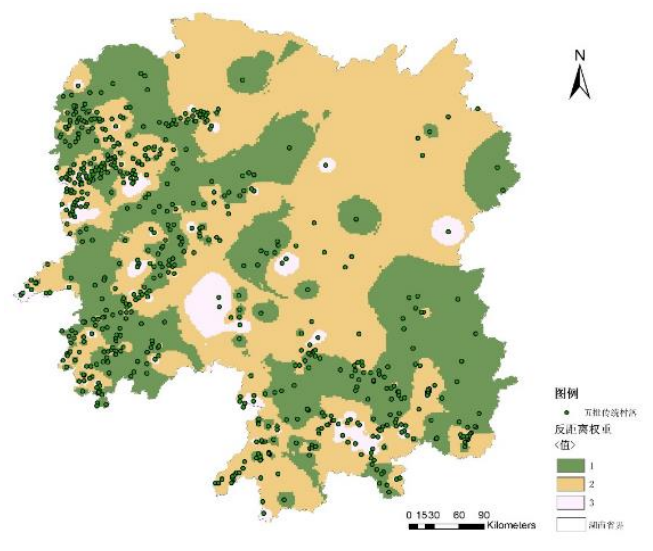

Fig. 2. Spatial Weighted Distribution of Traditional Villages and River Systems in Hunan Province

\subsection{Data Source and Processing}


658 national-level traditional villages and river systems of mainly branch basins in Hunan Province are analyzed as an example. The data comes from the traditional village network platform in China, and the latitude and longitude coordinates are obtained from the OspiderV3.0.1 software. The Digital Elevation Model (DEM) is aster ASTER GDEM V2 global digital elevation data from the Geospatial Data Cloud, with a resolution accuracy of 30m. and the DEM data was extracted by using ArcGIS 10.8 software. Then the map was vectorized to obtain the spatial distribution of traditional villages and river systems in Fig.1, and its attribute database was constructed. The indicator data of each city (prefecture) in Hunan Province comes from the Hunan Statistical Yearbook-2020 and the Hunan Statistical bulletin2020 on national economic and social development.

\subsection{Methodology}

\subsubsection{Spatial auto-correlation analysis}

In order to reveal whether there is spatial correlation between traditional villages and its adjacent river systems, a globle auto-correlation model is used to describle the agglomeration (positive correlation) and dispersion (negative correlation) of 658 traditional villages river systems (Mao et al.,2004).The positive and negative values of globle Moran's I index are often used for measurement and statistical judgment, and the formula is expressed as:

$$
I=\frac{n}{s_{0}} \frac{\sum_{i=1}^{n} \sum_{j=1}^{n} w_{i, j} z_{i} z_{j}}{\sum_{i=1}^{n} z_{i}^{2}}
$$

Where $i=$ the Moran exponent, $n=$ the total number of region, and $\mathbf{s}_{\mathbf{0}}=$ the aggregation of all spatial weights:

$$
\begin{aligned}
& S_{0=\sum_{i=1}^{n} \sum_{i=1}^{n} w_{i, j}} \\
& Z_{I=\frac{I-E[I]}{\sqrt{V[I]}}}
\end{aligned}
$$




$$
\boldsymbol{E}[\boldsymbol{I}]=-1 /(n-1), \boldsymbol{V}[\boldsymbol{I}]=E\left[I^{2}\right]-E[I]^{2}
$$

\subsubsection{Inverse distance weighted interpolation}

So as to intuitively reflect the distribution of spatial correlation agglomeration degree, the sites of traditional village in Hunan Province were overlapped with the discrete river systems data to obtain a differentiated correlation agglomeration surface map. The inverse distance weighted (IDW) interpolation is a common and simple method, which uses the form of surface to reflect the spatial correlation aggregation degree of traditional villages and river systems(Li et al.,2020). It is a weighted average of the weights. The greater the spatial correlation between site selection of traditional villages and river systems in Hunan Province, and vice versa.

The calculation formula of IDW interpolation is as follows:

$$
\begin{aligned}
& \boldsymbol{Z}_{\mathbf{0}}=\sum_{i=\mathbf{1}}^{n} \frac{\boldsymbol{Z}_{i}}{\boldsymbol{D}_{i}^{p}}\left(\sum_{i=\mathbf{1}}^{n} \frac{\mathbf{1}}{\boldsymbol{D}_{i}^{p}}\right)-1 \\
& \mathbf{D}_{\mathrm{i}}=\sqrt{\left(\mathrm{x}_{0}-\mathrm{x}_{1}\right)^{2}-\left(\mathrm{y}_{0}-\mathrm{y}_{1}\right)^{2}}
\end{aligned}
$$

Where $\mathrm{Zo}=$ the interpolation result of the attribute value whose coordinate points are located at (xi, yi); $\mathrm{Zi}=$ an attribute value of an $i-\operatorname{th}(i=1,2, \ldots, n)$ sample; $p$ is a power of distance, and $p=$ 2 is usually selected. $D i$ is the distance between the $i-t h$ sample point and the interpolation point.

\subsubsection{Buffer analysis}

Buffer analysis is a common element influence distance analysis method. Based on the point traditional villages and linear river systems, a polygon layer is established to describe the close spatial distance between the traditional villages and river systems. The spatial distance between the study and the water system is mainly divided into horizontal distance, vertical distance and hierarchical distance index to reflect the impact of defense, life, production and flood control on the location of traditional villages. Through buffer zone analysis, the overlay layer of traditional villages and river systems within a certain width is presented, and the spatial distance relationship between them is obtained. 


\subsubsection{Multivariate stepwise regression analysis}

Considering the influence effect of explanatory variables, the multi factor stepwise regression method can screen insignificant variables, obtain the optimal regression equation, increase the fitting degree of data, and then identify the key influencing factors of the spatial correlation between site selection and river systems (Lu,2002). The specific steps are as follows: select the explanatory variables, introduce the regression equation one by one according to the force on the explained variables, screen the explanatory variables with great influence, and use the least quadratic method to obtain the optimal regression equation. Multivariate stepwise regression model is a simple and effective method to find the dominant factors among a variety of influencing factors. The explanatory variables that have no significant impact on the explained variables are replaced by the degree of force(Long et al.,2019). The relationship between the influencing factors is expressed as:

$$
Y_{i}=b_{0}+b_{1} X_{1 i}+\cdots+b_{j i} X_{j i}+U_{i}
$$

In which $i$ is the sample size, $i=1,2, \ldots, b_{i j}$ is the equation variable coefficient, $j=1,2, \ldots, I ; U_{i}$ is the residual term.

\section{Results and Analysis}

\subsection{Auto-correlation feature of spatial}

Taking the longitude and latitude of 658 national traditional villages in Hunan Province and river systems extracted from hydrological analysis as the data source, the global spatial autocorrelation analysis is carried out. The results show that the Moran's I index is 0.5108 and passed the significance test at the level of 0.01. It also shows that there is a significant spatial positive correlation between traditional villages and river systems in Hunan Province, and the overall correlation is not random. That is, the high 
index area of river systems distribution is adjacent to the index area with high distribution of traditional villages, and vice versa.

It can be seen from Fig.1 that traditional villages have obvious distribution characteristics along the river systems, especially along the Yuan River and Xiangjiang River, which represents an ecological view of environmental adaptation of linear heritage corridor. River systems is an important element of traditional villages and plays an extremely important role in their survival and development. The spatial correlation between the two runs through the whole historical process. First, river systems provides material guarantee for residents' agricultural production and daily life; Second, based on the traffic function of river systems, many traditional villages have grown along river systems corridor.

\subsection{Density correlation feature of spatial}

The nearest neighbor analysis on site selection of traditional villages and river systems in Hunan Province was performed to obtain the distance between these points and the nearest river systems. The IDW spatial interpolation function was run in ArcToolbox to measure the correlation distance between site selection (all points) and river systems (unknown points) in Hunan Province based on the formulas (5) and (6), so as to get the inverse distance power value (that is, the weighted value, the function of the reciprocal of the distance) of each point. The higher this value is, the greater the spatial influence; on the contrary, the lower the influence is, or even no influence at all. The results are reclassified and assigned with the values of 1st, 2nd and 3rd level respectively. Further, the number of traditional villages in each level is calculated by using the selection method, among which there are 386 traditional villages in the $1^{\text {st }}$-level, 151 in the $2^{\text {nd }}$-level and 121 in the $3^{\text {rd }}$-level. It can be seen that the high-density value in the 1 st level takes up nearly $1 / 2$ of the total number, which demonstrates a significant spatial correlation in site selection between traditional villages and river systems, with a trend of aggregation in the mountainous 
areas of Xiangxi Prefecture, Zhangjiajie, Huaihua, Chenzhou, and Yongzhou, etc(Fig. 2).

The above analysis shows that the two high-density areas have overlapping mountains and staggered streams and rivers. Historically, they are areas where ethnic groups live together and Witch Chu culture is popular. In addition, the Fengshui environment concept is also a generator that affects the spatial relationship between traditional villages and river systems.

\subsection{Distance and Order Features of Spatial}

\subsubsection{Horizontal distance of spatial analysis}

Based on the DEM data of Hunan Province, river systems were converted to point elements. According to the current distance value basically covering all traditional villages and the empirical value of buffer zone distance setting in the existing research, the interval coefficient is set to $500 \mathrm{~m}$, and the multi ring buffer zone is analyzed(Zhou et al.,2017). In addition, the quantitative statistical method is adopted. It can be obtained from Table 1 that the horizontal distance between traditional villages and river systems is more than $1 / 2$ and less than 500m. Through further statistical analysis, a total of 339 are obtained. There are 107 in Huaihua, 81 in Xiangxi and 48 in Chenzhou. In addition, the number of site selection decreased with the increase in the horizontal distance from river systems, which shows that river systems is a key factor for site selection of traditional villages in Hunan Province.

According to the demand distance of residents' living and production irrigation water and the current location of traditional villages, the second level classification is carried out with $100 \mathrm{~m}$ as the interval coefficient. It can be seen from Table 2 that the number within $300 \mathrm{~m}$ accounts for half, which further shows the spatial characteristics of "living by river and prospering by river" in the site selection of traditional villages in Hunan Province. 


\subsubsection{Vertical distance of spatial analysis}

By measuring the nearest distance between the site selection of traditional villages and the point elements of river systems in Hunan Province, the intersection method of multi-ring buffer zones was then used to obtain the elevations between the elements of traditional villages and the nearest point of river systems. Finally, the vertical distance was obtained by spatial statistical subtraction.

As shown in Table 1, traditional villages are mainly concentrated within $20 \mathrm{~m}$ from the river systems, accounting for $80 \%$. It can be seen that the number of traditional villages gradually decreases with the increase of the vertical distance from the river systems. In addition, due to the close spatial correlation, the dynamic gravity flow of the river systems is often used for farmland irrigation in the mountainous areas where the traditional villages are densely distributed, which reflects the ecological wisdom of a traditional villages.

\subsubsection{River grade of spatial analysis}

According to the factors such as river shape and flow, the classification operation is carried out by using Strahler river network classification method to obtain a total of 5-level water system distribution map(Tang \& Yang,2017). The specific steps are as follows: DEM data without depression are obtained through depression filling and flow direction diagram is obtained through flow direction analysis; The concentration accumulation grid is obtained based on the above flow direction analysis data; Set the flow threshold to 800 to obtain the river network density; River digital classification and river network classification are carried out according to the concentration accumulation, the level is determined according to the concentration accumulation, and the properties of its main tributaries are determined accordingly; With the help of grid river network vectorization tool, the five-level river systems is obtained through hierarchical color. 
The results show that the Xiangjiang River, Zijiang River, Yuanshui River and Lishui River are Grade 5. Class 4 rivers include Youshui, Wushui, chenshui, Shushui, Qushui, Wushui and Xushui, the tributaries of the Yuan river channel, the main tributaries of the Li River are loushui, Shushui, Daoshui and Censhui, the larger tributaries of the Xiang River are Liuyang River, Laodao River, Jinjiang River and Shushui, and the main tributaries of the Zijiang River are Yuxi River, Longxi River, liaoshui, LongjiangRiver, tap water and Dejiang river. Grades 1-3 are other small tributaries.

Through the superposition of traditional villages point elements and river network classification map in Hunan Province, the river classification results are obtained by using spatial statistics and reclassification. The results show that the number of sites in Hunan Province decreases with the increase of level, mainly concentrated in first-class rivers, accounting for 95\% (Table 2). The climate flood season in Hunan Province is from April to August, and there are many floods. It can be seen that the site is selected to facilitate drinking water and avoid floods. Residents often live in low-level areas.

Table 1. Correlation between Site Selection of Traditional Villages and Their Horizontal and Vertical Distances from River Systems in Hunan Province

\begin{tabular}{|c|c|c|c|c|c|c|c|c|}
\hline \multirow{9}{*}{$\begin{array}{l}\text { Correlation wi } \\
\text { th Horizontal } \\
\text { Distance }\end{array}$} & $\begin{array}{c}\text { Distance } \\
\text { (m) }\end{array}$ & $\begin{array}{l}\text { Number } \\
\text { (Villages) }\end{array}$ & $\begin{array}{r}\text { Proportio } \\
(\%)\end{array}$ & $\begin{array}{l}\text { Density (Villag } \\
\text { es/10,000 } \mathrm{km}^{2} \text { ) }\end{array}$ & \multirow{9}{*}{$\mid \begin{array}{c}\text { Correlation wi } \\
\text { th Vertical Di } \\
\text { stance }\end{array}$} & \multicolumn{2}{|c|}{ Distance/m Number/Villages } & Proportion $1 \%$ \\
\hline & $0-500$ & 384 & 58.36 & 65.03 & & $-40--20$ & 38 & 5.78 \\
\hline & $500-1000$ & 55 & 8.36 & 8.19 & & $-20--0$ & 114 & 17.33 \\
\hline & $1000-1500$ & 58 & 8.81 & 7.65 & & $0-20$ & 239 & 36.32 \\
\hline & $1500-2000$ & 61 & 9.27 & 7.18 & & $20-40$ & 84 & 12.77 \\
\hline & $2000-2500$ & 34 & 5.17 & 3.60 & & $40-60$ & 38 & 5.78 \\
\hline & $2500-3000$ & 27 & 4.10 & 2.59 & & $60-80$ & 23 & 0.91 \\
\hline & $3000-4000$ & 25 & 3.80 & 1.05 & & $80-100$ & 20 & 3.50 \\
\hline & $>4000$ & 14 & 2.13 & - & & $>100$ & 102 & 15.50 \\
\hline
\end{tabular}

Table 2. Correlation between Site Selection of Traditional Villages and Their Horizontal Distance (0-500m) from and Level of River Systems in Hunan Province

\begin{tabular}{|c|c|c|c|c|c|c|c|c|c|}
\hline $\begin{array}{l}\text { Correlation } \\
\text { with Horizon } \\
\text { tal Distance }\end{array}$ & $\begin{array}{c}\text { Distance } \\
\text { (m) }\end{array}$ & $\begin{array}{l}\text { Number } \\
\text { (Villages) }\end{array}$ & $\begin{array}{c}\text { Proportion } \\
(\%)\end{array}$ & $\begin{array}{l}\text { Density (Vill } \\
\text { ages/10,000 k } \\
\left.\mathrm{m}^{2}\right)\end{array}$ & \multirow{3}{*}{$\begin{array}{c}\text { Correlation wi } \\
\text { th Level and } \\
\text { Density }\end{array}$} & $\begin{array}{c}\text { River Syste } \\
\text { m Level }\end{array}$ & $\begin{array}{r}\text { Number ( } \\
\text { ages) }\end{array}$ & $\begin{array}{l}\text { oportion } \\
(\%)\end{array}$ & $\begin{array}{l}\text { Density (Vill } \\
\text { ages/10,000 k } \\
\mathrm{m}^{2} \text { ) }\end{array}$ \\
\hline (within $0-50$ & $0-100$ & 96 & 14.59 & 86.05 & & 1st-level & 559 & 95.39 & 158.91 \\
\hline 0 Meters) & $100-200$ & 93 & 14.13 & 80.85 & & 2nd-level & 47 & 8.02 & 33.68 \\
\hline
\end{tabular}




\begin{tabular}{|c|c|c|c|c|c|c|c|}
\hline $200-300$ & 77 & 11.70 & 5.76 & 3rd-level & 28 & 4.26 & 39.28 \\
\hline $300-400$ & 45 & 6.84 & 37.10 & 4th-level & 20 & 3.04 & 33.99 \\
\hline $400-500$ & 73 & 11.09 & 58.68 & 5th-level & 4 & 0.61 & 19.11 \\
\hline
\end{tabular}

\section{Analysis on the Main Influence Mechanism}

\subsection{Construction of influencing factors and multi-factors regression model}

\subsubsection{Analysis of influencing factors}

In order to identify the key influencing factors and analyze their degree of the spatial correlation between traditional villages and river systems. In addition, considering that the sample area with closer spatial correlation can be better tested. Therefore, based on the above reasons, this study mainly takes 384 traditional villages within 500m away from the horizontal spatial distance with river systems as the explanatory variable, and takes the impact index values corresponding to 61 districts and counties to analyze the correlation and construct a multi-factors stepwise regression model.

Based on the existing research on "traditional village site selection and river systems", especially the connotation research on the application of site selection (Cao \& Feng,2014;Xin et al.,2020;Duan et al.,2021), and in view of the availability of data, the main influencing factors of spatial correlation are attributed to three target indexes: natural environment, socio economic and cultural foundation, and six influencing factors index layers are constructed based on the above three dimensions, mainly including precipitation, elevation, per-capita GDP, urbanization level, farming industry and minority population. In addition, the index data involved are at the county level. Among them, precipitation and elevation are geomorphic environment, which have a direct impact on the characteristics of river systems. They are also the natural carrier of the association; Due to the spatial 
obstacles of ecological environment, the material information flow at the social level of traditional villages is affected. Therefore, per capita GDP and urbanization level are the social characteristics of the background of spatial pattern to a certain extent(Ma \& Huang,2017); Farming industry have a direct demand relationship for water resources. According to the type and actual situation of current agricultural development, they are selected as the reference of regional economic environment(Fan et al.,2009); The population of minorities reflects the sustainable growth based on river cultural beliefs of residents(Li,2001).

\subsubsection{Establishment of multivariate stepwise regression}

Due to the comprehensiveness of each factor can not be guaranteed, exploratory analysis is mainly adopted, and the main factors can be effectively judged through multi-factors stepwise regression analysis. According to the relevant index data of the counties to which the selected samples belong in 2020, calculated by SPSS regression model, the results are shown in Table 3. Among the six selected index factors, elevation, per capita GDP, farming industry and minority population have a significant impact on the spatial correlation between them, and sig passed the 0.05 level test. Through further regression calculation and equation fitting of different influencing factors, Table 4 is obtained. Combined with the significance value, elevation, farming industry, and ethnic minority are selected as the main influencing factors. Adjusted regression equation $R 2=0.324, f=$ 10.577 ( $\alpha=0.000$ ), the fitting degree of regression equation is good.

Further, Table 4 is obtained through SPSS stepwise regression. Combined with the results in Table 4, the simulation equation is expressed as:

$$
Y=10.508+0.332 X_{2}+0.203 X_{4}+0.37 X_{6}
$$

In the multi-variate stepwise regression model analysis, each index data is standardized. The 
greater the significance value, the greater the influence on the dependent variable. This study shows that the main influencing factors of the spatial correlation are minority population > elevation > farming industry.

Table 3. Main Influencing Factors of Spatial Correlation between Site Selection of Traditional Villages and River Systems in Hunan Province

\begin{tabular}{|c|c|c|c|c|c|c|}
\hline Objective & Code & Criteria & Indicators & $\begin{array}{l}\text { Person } \\
\text { Value }\end{array}$ & $\operatorname{sig}$ & Indicator Meaning \\
\hline & $\mathrm{X} 1$ & $\mathrm{Fn}$ & Rainfall/mm & 0.037 & 0.780 & Reflecting the natural foun- \\
\hline $\begin{array}{l}\text { Influencing Factors } \\
\text { of Spatial Correlation }\end{array}$ & $\mathrm{X} 2$ & vironment & Evaluation/m & $0.341 * *$ & 0.007 & $\begin{array}{l}\text { dation for spatial growth of } \\
\text { the villages and river systems }\end{array}$ \\
\hline between Site Selec- & $\mathrm{X} 3$ & & per capita GDP/yuan & -0.122 & 0.349 & Reflecting the socio-eco- \\
\hline tion of Traditional & $\mathrm{X} 4$ & & Urbanization Level /\% & $-0.319 *$ & 0.012 & nomic impact under the ac- \\
\hline Villages and River & $\mathrm{X} 5$ & 100 & Farming industry $/ \mathrm{mm}$ & $-0.364 * *$ & 0.004 & tion of the water environment \\
\hline $\begin{array}{c}\text { Systems in Hunan } \\
\text { Province }\end{array}$ & X6 & $\begin{array}{c}\text { Cultural } \\
\text { Foundation }\end{array}$ & $\begin{array}{l}\text { Minority Popula- } \\
\text { tion/10,000 People }\end{array}$ & $0.485 * *$ & 0.000 & $\begin{array}{l}\text { Reflecting the historical car- } \\
\text { rier for spatial growth of vil- } \\
\text { lages and river systems }\end{array}$ \\
\hline
\end{tabular}

Table 4. Regression Analysis on the Main Influencing Factors of Spatial Correlation between Site Selection of Traditional Villages and River Systems in Hunan Province

\begin{tabular}{cccccc}
\hline Entering Variable & Regression Coefficient (B) & $\begin{array}{c}\text { Standard Partial Regression } \\
\text { Coefficient }(\beta)\end{array}$ & \multicolumn{2}{c}{ Significance } \\
Evaluation/m & 2.773 & 0.332 & 3.067 & 0.003 & 1.014 \\
per capita GDP /yuan & -2.601 & -0.274 & -2.878 & 0.045 & 1.245 \\
Minority Popula- & 3.097 & 0.387 & 3.135 & 0.003 & 1.207 \\
tion/10,000 People & & & & & \\
\hline
\end{tabular}

\subsection{Analysis of Main Influencing Factors and Influence degree}

\subsubsection{Minority population}

The absolute value of the correlation is the highest (Pearson correlation coefficient is 0.485 ), and there is a significant positive correlation ( $\mathrm{SIG}=0.000$, pass the 0.05 level test), indicating that the minority population has the strongest impact on the spatial correlation, that is, history and culture is the basis of the stability of the spatial correlation. Traditional cultures such as Fengshui beliefs of different nationalities determine the subjective choice of water environment in traditional villages, reflecting their 
national cultural characteristics(Wang,2005;Yan et al.,2021). The spatial correlation is formed by human active intervention in the process of site selection. Historically, Dongting Lake undertook the migration of northern nationalities to the south. According to the records of Hanshu geographical records, the ancient Yue people widely lived in the coastal area south of the Yangtze River. The upper reaches of Lishui River basin where Chengtoushan site is located, and the Ganlan architectural form guided by the river can still be seen everywhere in the Tujia area of Western Hunan(Xiong,2007). Traditional villages in Hunan Province are gathered by 8 ethnic minorities, including Miao, Tujia, Dong, Yao and Bai. The worship of nature in ethnic settlements is manifested in the spatial order of "mountain-house-field-river -mountain", which reflects the concept of Fengshui, which is the location theory of ancient Chinese settlements(Sun \& Xu,1996). It can be seen that national culture is an important cultural basis for their spatial correlation.

\subsubsection{Elevation}

From the correlation value analysis, the correlation coefficient of elevation is 0.341 , showing a significant positive correlation ( $\mathrm{SIG}=0.007$, passing the 0.05 level test). Hunan is surrounded by mountains from east to west and south, belonging to the transition zone from Yunnan Guizhou Plateau to Jiangnan hills and from Nanling Mountain to Jianghan Plain. The terrain differentiation is obvious, and the highaltitude areas are concentrated in the Nanling Mountains in southwestern Hunan and the Wuling mountains in southern Hunan, both of which are more than 1000 meters. Based on Fig. 2 and the elevation data of each district and county, it can be seen that the area with the highest spatial correlation density between traditional villages and water systems in Hunan Province is located in the mountainous and hilly areas in Western and southern Hunan. Most rivers are formed by short-term rainfall, and the flat terrain is mixed with small valleys. The characteristics of undulating mountains, abundant precipitation and humid climate in high-altitude areas are the decisive factors affecting the spatial relationship between 
traditional villages and water systems. It can be seen that the location of high-altitude location of traditional villages is conducive to the adaptation of mountain crop cultivation to the natural environment of river systems, military defense, and provides a natural barrier to prevent flood disasters, reflecting the ecological wisdom of harmony between traditional villages and nature.

\subsubsection{Farming industry}

The Pearson correlation coefficient of farming industry value is -0.319 , and there is an obvious negative correlation ( $\mathrm{SIG}=0.012$, passing the 0.05 level test). The farming industry is an important index to measure the total scale of agricultural production dominated by agriculture such as rice, vegetables and fishery breeding. Based on Fig. 2 and sorting out the output value of agriculture, forestry, animal husbandry and fishery in each county (District), Xiangxi Prefecture, Zhangjiajie, Shaoyang, Yongzhou and Huaihua are also areas with relatively low output value of farming industry. In addition, it is attributed to the strong dependence of farmland irrigation on water, and river systems affect the accessibility of traditional villages, resulting in the lag of regional economic development. It can be seen that farming industry structure dominated by agricultural production for a long time is a negative and strong correlation factor affecting the spatial correlation.

\section{Conclusions}

To protect and reconstruct the river adaptability space of traditional villages, this study builds an awareness of spatial culture from which adopts spatial cognitive approaches to extract spatial texture. The quantitative method introduced in this paper mainly deals with two issues: one is to understand spatial auto-correlation and structure features of river adaptability, also interpret influence mechanism that can help cognitive local culture; the other is to verify the Fengshui idea of village site selection of “pillow mountain, ring water and face screen"(Jin et al.,2002), and reveal the site selection gene of the 
river adaptability of traditional villages. This study can draw the conclusions as follows:

First of all, there is a significant spatial positive correlation between traditional villages and river systems. It shows the pattern of "multi belt distribution along the tributaries of the Yuan River and the Xiangjiang River Basin". There are two aggregation areas in spatial correlation: one is located in the mountain space between Wuling and Xuefeng mountains in Western Hunan; The other is located in the low mountain and hilly area of southern Hunan. Among them, the maximum correlation density value is located in the ecologically fragile mountain area space, which is facing the risk of ecological security; The minimum correlation density value is located in the plain area with strong interference of human economic activities, which has high traffic sensitivity.

Secondly, the spatial distribution of the association between traditional villages and river systems presents a ladder structure, with significant vertical differences. It is mainly reflected in the spatial distance and distribution from river systems. Among them, the spatial distance is divided into horizontal and vertical distances. The study shows that the close value of the spatial distance accounts for a large proportion, but the number of traditional villages decreases with the increase of the spatial distance. The areas with large close value are mainly located in the mountainous spatial areas of Xiangxi Prefecture and Huaihua City; In addition, traditional villages show a distribution trend associated with low river systems level, and the original river systems characteristics of natural environment are the key influencing factors of their distribution characteristics. In the context of rural spatial reconstruction, the spatial security pattern should be constructed from multi-dimensional and multi-level aspects such as watershed heritage corridors. In addition, the regional advantages such as springs, streams and mountain streams formed by different landforms should be integrated to activate the spatial interaction vitality of "traditional villages+river”. 
Finally, it is concluded that the spatial relationship is significantly affected by three factors: Mountain natural environment, national main feng shui culture and regional economic development, and there are spatial differentiation characteristics. Among them, the elevation is the key factor of spatial correlation; The location of minority subject is influenced by the thought of Feng Shui ritual system, which is the subjective factor of spatial correlation; The type and development degree of regional economy are the positive key factors affecting the survival texture. Due to the impact of each index factor on the correlation between traditional villages and river systems in different regional spaces, the differentiation shows different intensity. In the future research, we can further identify the spatial visualization layer of each index factor and establish a spatial correlation database to better guide the protection and transformation of the adaptability of river systems.

However, there are still some deficiencies in this study:we should improve the accuracy and integrity of data information acquisition, and further enrich the dialectical influencing factors of the spatial correlation; Expand the research on the spatio temporal dynamic evolution mechanism, and predict the development model of the applicability of river systems in the future; Strengthen the spatial and local research in different regions.

\section{Acknowledgments}

The authors would like to thank the rural revitalization research group of Hunan University of Technology for providing their valuable comments.

\section{ORCID}

Suifeng Zhang http://orcid.org/0000-0001-9417-3612

\section{References:}

Bai,L.N.(1935).Principles of human geography,translated by Ren Meijing,Li Xudan.Zhongsh publishing 
house,Nanjing,China,10-27(in Chinese)

Cao,F.G.,Feng,W.B.(2014).Comparative study on site selection of traditional settlements based on Fengshui and GIS: Illustrated by Longxing ancient town in Chongqing. Journal of $C$ hongqing Normal University(Natural Science) 31(3):119-124+145,DOI:10.11721/cqnuj201403 25(in Chinese)

Duan,S,Xie,J,Wang,H,Wu,H.(2021).Traditional villages planning thought and its inspiration. Chinese Journal of Agricultural Resources and Regional Planning 42(1):203-209,DOI:10.7621/cjarrp.10059121.20210124(in Chinese)

Feng,Y.B.,Long,H.L.(2020).Research progress and prospect of spatial reconstruction of rural settl ements in Mountainous Areas of China. Progress in Geography 39(5):866-879,DOI:10.1830 6/dlkxjz.2020.05.014(in Chinese)

Fan,F,Wu,D.W.,Chen,T.Z.(2009).Analysis on influencing factors of rural settlement location. Journal of Hainan Normal University(Natural Science Edition) 22(4):462-467(in Chinese)

Gao,Y,Yang,D.H.,Zhang,R.H.,Gao,Y.J.(2021).Spatial form and cultural characteristics of traditiona water accumulation adaptability in Hainan Island. New Building (2):126-129,DOI:10.12069/j. na.202102126(in Chinese)

Gilman,R.(1991).The Eco-village challenge. Living Together 29(2):10-11

Hu,B.B.,Li,X.B.,Wang,X.B.(2007). Investigation report on the protection of traditional villages in China. Social Sciences Academic Press, Beijing,China,1-5(in Chinese)

Jin,Q.M.(1988). Rural settlement geography.Science press,Beijing,China(in Chinese)

Ji,R.,Ding,J.H.(2019).Reconstruction of rural spatial form in southern Jiangsu based on the supply-demand relationship of water ecosystem services. Planner 35(20):863-872(in Chinese)

Jin,T.,Zhang,X.L.,Jin,B.(2002).Analysis of Chinese traditional rural settlement construction thought. Human Geography 17(5):45-48,DOI:10.13959/j.issn.1003-2398.2002.05.011(in Chinese)

Li,H.B.,Zhang,X.L.(2012). Research progress and recent trend of rural settlement geography abroad. Human Geography 27(4):103-108,DOI: 10.13959/j.issn.1003-2398.2012.04.027(in Chinese)

Li,S.S.,Ma,Y.F.,Guo,Y.S.,Du,J.,Wang,D.F.(2019).The relationship between the distribution features of ancient settlements in pre-west Zhou Dynasty and the changes of rivers and lakes in Zheng zhou. Regional Research and Development 38(6):171-176,DOI:10.3969/j.issn.1003-2363.2019.0 6.031(in Chinese)

Liu, C.,Wang,S.S.,Li,J.Q.,Wu,W.H.,Li,H.Y.(2017).Study on the spatial pattern of the applicability of traditional water gathering-Taking the ancient city of Taierzhuang as an example. Modern urban research (4):75-81,DOI:10.3969/j.issn.1009-6000.2017.04.012(in Chinese)

Liu,B..Y,Zhou,J.(2004).On bank protection planning and design in landscape water system regulation. Chinese Garden (3):49-52(in Chinese)

Lu,J.,Xu,K.H.,Wang,A.I.J.(2017).Study on the suitability of settlement spatial distribution based on quantitative model-Taking Jiaohe City of Jilin Province as an example. Urban Architecture, (7):112-116,DOI:10.19892/j.cnki.csjz.2017.07.019(in Chinese)

Li,B.H.,Yin,S.,Liu,P.L.,Dou,Y.D.(2015).Spatial distribution characteristics and influencing factors of traditional villages in Hunan Province. Economic Geography 35(2):189-194,DOI:10.1595 7/j.cnki.jjdl.2015.02.027(in Chinese)

Li,X.B.(2001).Cultural geographical vision of ancient Fengshui model in China. Human Geography 16(6):64-68,DOI:10.13959/J.ISSN.1003-2398.2001.06.017(in Chinese)

Li,X.X.,Zhu,W,Zhang,Z.H.,Hu,Y.N.(2020).Study on the spatial correlation between soil Cr content and 
land use based on information entropy. Journal of ecology and rural environment 36(11):14371443,DOI:10.19741/j.issn.1673-4831.2020.0068(in Chinese)

Lu,W.D.(2002).SPSS for windows statistical analysis. Electronic Industry Press, Beijing,China(in Chinese)

Long,F.,Liu,J.M.,Zhu,H,Li,T.(2019).Spatial distribution and influencing factors of home stay in the Yangtze River Delta. Journal of Geography 38(4):950-960,DOI:10.11821/dlyj020180308(in Chinese)

Ma,Y,Huang,Z.X.(2017).Research on the spatial pattern and accessibility of traditional villages inurban agglomerations in the middle reaches of the Yangtze River based on GWR model. $H$ uman Geography 32(4):78-85,DOI:10.13959/J.ISSN.1003-2398.2017.04.011(in Chinese)

Mao,Z.Y.,Li,L.(2004).Measurement and application of spatial model. Science Press,Beijing,China,6364(in Chinese)

Palang,H.,Helmfrid,S.,Antrop,M., Alumae,H.(2003).Rural landscape:past process and future strategies, Landscape and Urban Planning,70(1):3-8,DOI:10.1016/j.landurbplan.2003.10.001

Stone,G.D.(1996).Settlement ecology:the social and spatial organization of Kofyar agriculture,University of Arizona Press,Tucson,USA,6-21

Song,J.J.,Yang,R.B.,Li,Y.M.(2016).Spatial construction of traditional settlements in Tongdao Dong autonomous county. Ecological Science 36(3):863-872,DOI:10.5846/stxb201408261698(in Chinese)

Sun,T.S.,Xu,D.X. (1996) .Research on Fengshui-A theory of Ancient settlements location of China. Human Geography S2(10):60-62,DOI:10.13959/j.issn..1003-2398.1996.s2.019(in Chinese)

Tang,G.A.(2000).Study on the spatial distribution law of rural settlements based on GIS-Taking Yulin area in Northern Shaanxi as an example. Economic geography 20(5):1-4,DOI:10.159 57/j.cnki.jjdl.2000.05.001(in Chinese)

Wu,Q.Z.(2002).Historical experience and reference of flood control in ancient cities of China. Urban planning 26(4):84-92(in Chinese)

Wang,Q.H.(2005).Research on Fengshui theory. Tianjin University Press, Tianjin,China,44-52(in Chinese)

Xu,F.,Deng,Y.,Xu,N.,Song,L.M.(2020).Research on the combination difference of traditional wate rfront villages in Hunan. Huazhong Architecture 38(7):104-111,DOI:10.13942/j.cnki.hzjz.202 0.07.023(in Chinese)

Xin,X.,Lu,H.,Xia,Q.,Ren,L.J.(2020).Study on the impact of Tibetan water culture on settlement s pace. Journal of western human settlements 35(5):125-131,DOI:10.13791/j.cnki.hsfwest.2020 0517(in Chinese)

Xiong,J.(2007).Dongting world water culture. Hunan University Press,Changsha,China(in Chinese)

Yang,L.(2002). From obtaining water to controlling water -- an analysis of the application of Feng Shui method in ancient urban construction. City Planning Review 26(1):79-84(in Chinese)

Yan,P.,Cheng,K.,Yang,J.T.(2021).Study on the cultural space of Hehuang traditional settlement inQinghai. HuaZhong Architecture 39(7):117-121,DOI:10.13942/j.cnki.hzjz.2021.07.024(in Chinese)

Yang,W.B.,Wang,M.Y.(2020).Organic adaptation of spatial form of traditional settlements and water environment in northern mountainous areas-Taking Houlinhe village of Wu'an city as an example. Urban Architecture 17(13):29-32+49,DOI:10.19892/j.cnki.csjz.2020.13.005(in Chinese)

Yu,K.J.,Zhang,L.(2007)Flood experience and adaptability landscape of ancient towns in the Yellow River flood plain. Urban Planning Forum 171(5):85-91(in Chinese)

Yan,L.J.,Shi,Y.S.,Lu,P.,Liu,C.L.(2017).Study on the relationship between prehistoric settlements site 
selection and River around Songshan Mountain Area. Areal Research and Development 36(2):169174(in Chinese)

Yin,H.Q.(2010).The route of Hunan traditional trade. Hunan Normal University Press,Changsha, China,63-83(in Chinese)

Zhang,J.(2012).Tracing the origin of ancient Chinese space culture,Tsinghua University Press,Beijing,China,76-106(in Chinese)

Zhang,J.(2015).On the protection of China's historical urban heritage network.Shanghai Uraban Planning Review (5):23-29+42(in Chinese)

Zhang,J.H.,Wang,L.N.(2007).Study on spatial environment and landscape types of spring settlement in Jinan spring city. Journal of Architecture (7):85-88(in Chinese)

Zeng,H.Z.,Zhang,C.,Zhao,M.(2020).Research on site selection and morphological characteristics of traditional settlements under the influence of Yuan River in Hunan. Modern Urban Research (3):5460,DOI:10.3969/j.issn.1009-6000.2020.03.008(in Chinese)

Zhou,H.,Wen,Y.Q.,Wu,G.Z.(2015).Research on the Yuan River Ancient channel and ancient towns along the Yuan River in Hunan from the perspective of cultural routes. New Architecture (6):105107(in Chinese)

Zhang,S.Y.,Wang,X.R.(2017).Study on spatial characteristics of Ningbo City under the influence of regional water system. Chinese Gardens 33(11):47-52(in Chinese)

Zhang,W.R.(1995).Research on historical and cultural geography of Hunan. Fudan University Press, Shanghai,China(in Chinese)

Zhou,Z.X.,Wang,X.D.,Qian,Y.(2017).Research on spatial distribution of the mountainous settlements in Karst Valley based on GIS: A case study of Baishui River valley in Guizhou. Design Community, (1): 14-22(in Chinese)

Zhou,T.(2008).Research on the Correlation between Water and rural space in Western Hunan. Doctor Thesis, Hunan University, Changsha,China(in Chinese) 